\title{
3. On Land Deformations accompanied by the Nosiro Earthquakes of 1694 and 1704.
}

\author{
By Akitune Imamura, M.I.A. \\ Seismological Institute, Tokyo Imperial University. \\ (Comm. Jan. 13, 1936.)
}

In the littoral of the Mutu-Dewa district in N. Japan, destructive earthquakes occurred one after another in a belt skirting Volcano Iwaki, the most notable having been the Nosiro earthquakes of 1694 and 1704, the Tugaru earthquake of 1766, and the West Tugaru earthquake of 1793. Not without significance, in this connection, are the eruptions of Iwaki-san, that occurred during 1596-1605, 1709, 1770, 1783-1807, and 1833-1863, repetitions of slow accumulation and sudden release of telluric stresses respectively preceding and following each subterranean convulsion. Further, every activity, whether seismic or volcanic, must have been accompanied by land deformation, which possibly migrated from one active locality to another, just as we have actually witnessed in the case of the Ito earthquake swarms and the destructive N. Idu earthquake, both of 1930 . Although studies in this direction may constitute an important part of observational seismology, it is unfortunate that the old records scarcely contain accurate informations that would be of any value. The present study was therefore undertaken with the object of supplying as much as possible of the deficiency.

The reason for selecting the two particular earthquakes in the present study is that they originated on or near the line of levels that links Akita on the south with Iwasaki on the north, a new line of levels having been run last year. The southern part of the line, namely, the section linking Akita with Nosiro, about $62 \mathrm{~km}$. in length, was first run in 1900 , while the northern, about $60 \mathrm{~km}$. in length, was run three years later. Diagrams in Fig. 2 indicate changes in landlevel undergone during the recent 35 and 32 years respectively. ${ }^{1)}$ The diagrammatic characteristies that are likely to be connected with the two earthquakes are as follows:

1) Scarcely any definite feature is indicated in connection with the 1694-earthquake. The level line merely seems to come in contact with the meizo-seismic area, while another level line, linking Nosiro with Aomori via Oodate, is likely to cross it.

2) The northern section crosses the meizo-seismic area of the 1704earthquake. The changes in land-level undergone during the recent 32 years are, broadly speaking, in positive correlation with those that occurred with the earthquake in question. Besides, the boundaries of minor blocks are indicated at several points, every block undergoing a northward tilt in the northern part of the area. Since the maximum secular elevation undergone during the recent 32 years works out to $3.3 \mathrm{~cm}$.,

1) With the same datum line as in my previous note: Proc. 11 (1935), 51-54. 


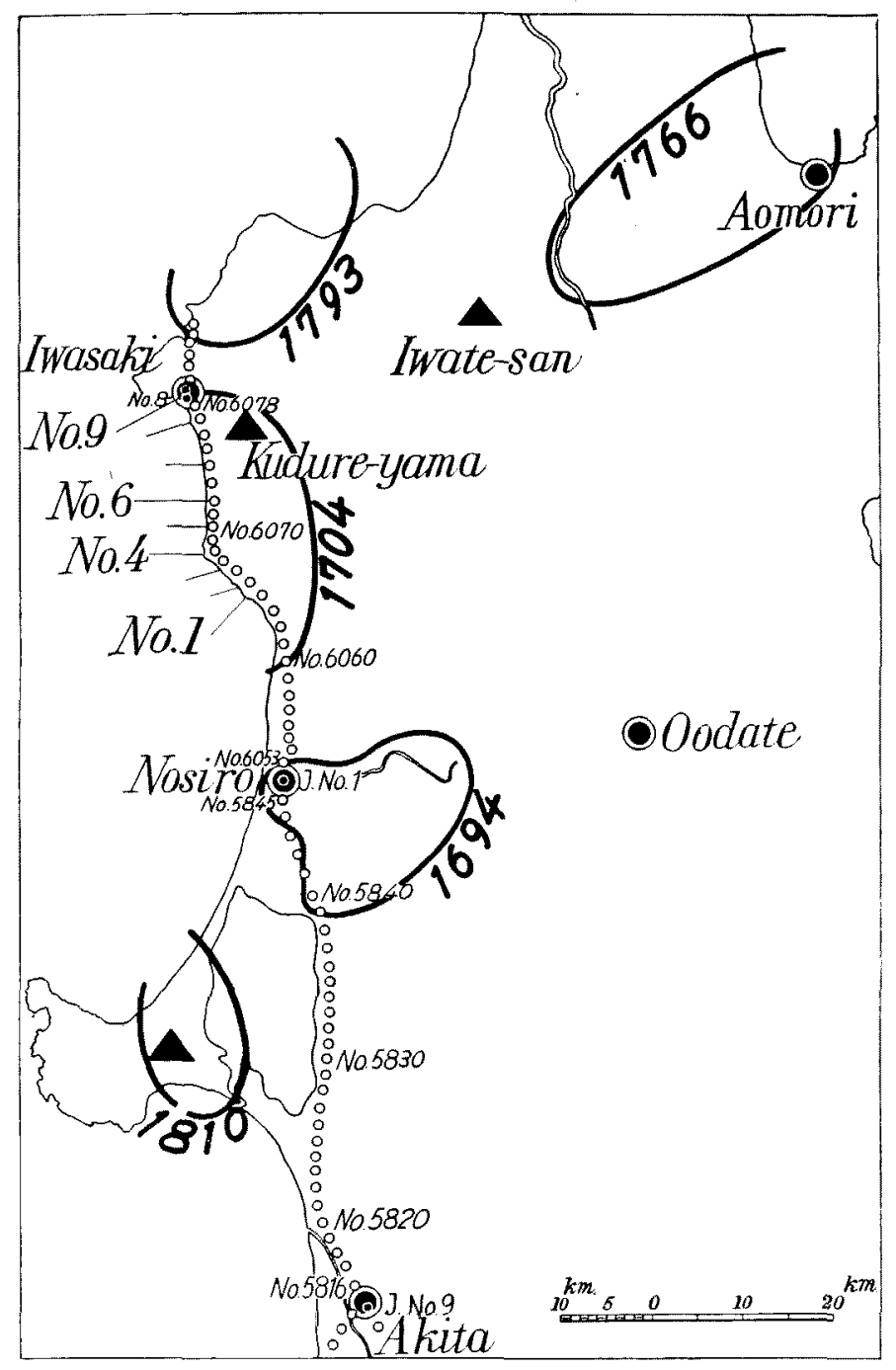

Fig. 1.

it may be assumed that the amount undergone since the 1704-earthquake will not exceed $30 \mathrm{~cm}$.

It is noteworthy that with the 1704-earthquake occurred two extraordinary topographic changes, the one a gigantic landslide that started near the summit from the western flank of Mt. Kuromori (now Kudure-yama), about $940 \mathrm{~m}$. high, and overwhelmed an area of about $16 \mathrm{sq.} \mathrm{km}$., now famous among limnologists as the Zyûni-ko (Twelve Lakes). The other is an upheaval of land traceable along the seaside of the meizo-seismic area. The results of my studies over a distance of about $34 \mathrm{~km}$. from Sigeura (No. 1) on the south to Iwasaki (No. 9) on the north show the rises to be; No. 1, Sigeura $120 \mathrm{~cm}$. No. 2, $160 \mathrm{~cm}$. No. 3, Iwadate $170 \mathrm{~cm}$. No. 4, $190 \mathrm{~cm}$. No. $5,160 \mathrm{~cm}$. No. 6, Oomagosi $140 \mathrm{~cm}$. No. 7, Kurosaki $130 \mathrm{~cm}$. No. 8, Moriyama $70 \mathrm{~cm}$. No. 9, Iwasaki $60 \mathrm{~cm}$.

In conclusion, I wish to express my sincere thanks to the Council of the Imperial Academy for granting me aid in the prosecution of the present study. 
No. 1.] On Land Deformations Accompanied by the Nosiro Earthquakes.

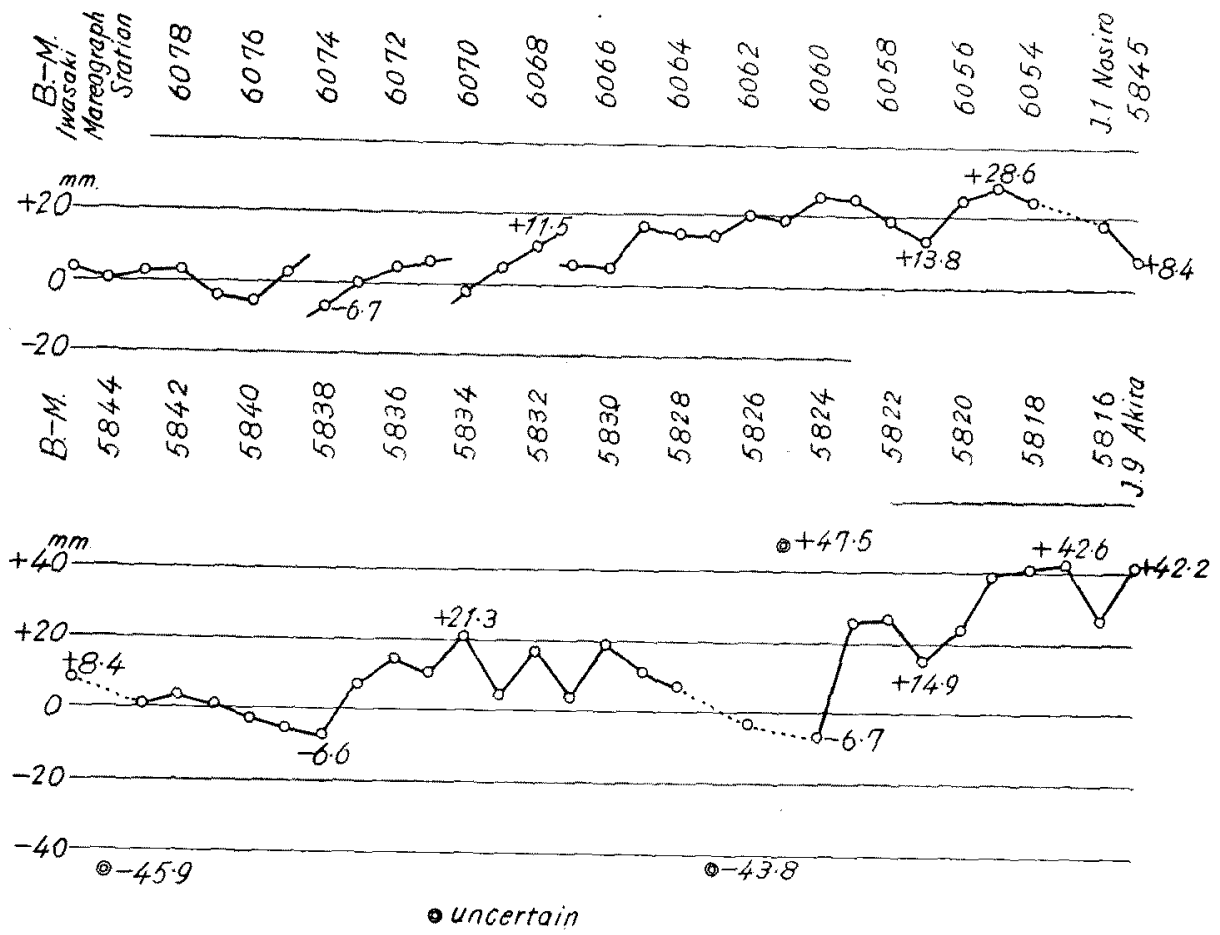

Fig. 2. 